\title{
Primary blood-hosts of mosquitoes are influenced by social and ecological conditions in a complex urban landscape
}

\author{
Heather Goodman', Andrea Egizi ${ }^{1}$ Dina M. Fonseca ${ }^{3}$, Paul T. Leisnham ${ }^{4}$ and Shannon L. LaDeau ${ }^{*}$
}

\begin{abstract}
Background: Temperate urban landscapes support persistent and growing populations of Culex and Aedes mosquito vectors. Large urban mosquito populations can represent a significant risk for transmission of emergent arboviral infection. However, even large mosquito populations are only a risk to the animals they bite. The purpose of this study is to identify and assess spatial patterns of host-use in a temperate urban landscape with heterogeneous socio-economic and ecological conditions.

Results: Mosquito blood meals were collected from neighborhoods categorized along a socio-economic gradient in Baltimore, MD, USA. Blood meal hosts were identified for two Aedes (Ae. albopictus and Ae. japonicus) and three Culex (CX. pipiens, $C x$. restuans and CX. salinarius) species. The brown rat (Rattus norvegicus) was the most frequently detected host in both Aedes species and Cx. salinarius. Human biting was evident in Aedes and Culex species and the proportion of human blood meals from Ae. albopictus varied significantly with neighborhood socio-economic status. Aedes albopictus was most likely to feed on human blood hosts (at 50\%) in residential blocks categorized as having income above the city median, although there were still more total human bites detected from lower income blocks where Ae. albopictus was more abundant. Birds were the most frequently detected Culex blood hosts but were absent from all Aedes sampled.

Conclusions: This study highlights fine-scale variation in host-use by medically important mosquito vectors and specifically investigates blood meal composition at spatial scales relevant to urban mosquito dispersal and human exposure. Further, the work emphasizes the importance of neighborhood economics and infrastructure management in shaping both the relative abundance of vectors and local blood feeding strategies. The invasive brown rat was an important blood source across vector species and neighborhoods in Baltimore. We show that social and economic conditions can be important predictors of transmission potential in urban landscapes and identify important questions about the role of rodents in supporting urban mosquito populations.
\end{abstract}

Keywords: Arbovirus, Avian, Blood meal, Human, Mosquito, Rat, Vector

\section{Background}

The establishment of an endemic West Nile virus (WNV) cycle involving Culex mosquito vectors across the United States and the global spread of Aedes mosquitoes have dramatically changed the landscape of arboviral risk in temperate cities [1-7]. Urban landscapes are a mosaic of land cover, with land-use varying from abandoned and unmanaged to highly managed and engineered sites [8], and

\footnotetext{
* Correspondence: ladeaus@caryinstitute.org

${ }^{1}$ Cary Institute of Ecosystem Studies, Millbrook, NY 12545, USA

Full list of author information is available at the end of the article
}

where human-influenced resource availability and disturbance can limit establishment of some species while favoring others, including medically important mosquito vectors [9-11]. When vector mosquito species reproduce and develop in residential landscapes, the adult females emerge and initiate blood-seeking behavior in close proximity to human and peridomestic animal hosts. Host-use (and specifically human biting rate) is a well recognized and important parameter in infectious disease models and transmission management strategies [12, 13].

Local transmission of arboviruses depends on female mosquitoes biting an infected host and then surviving 
long enough to bite again. This can occur via sequential human biting (i.e. dengue, Zika viruses) or in the case of WNV, the mosquito must bite the zoonotic (avian) reservoir before feeding from a human [14]. The probability of these specific biting sequences occurring depends on mosquito behavior or innate preferences, relative host availability, and adult mosquito longevity [15]. While studies clearly demonstrate that temperate urban habitat can support population growth of some mosquito species [7, 16-18], there is less consensus regarding the spatial generating mechanisms and consequences of host-use variation across urban landscapes.

Temporal and spatial variation in host-use (defined as the relative proportion of blood meals taken from a given host species in a sampled mosquito population) has been shown to influence the timing and potentially, the intensity of WNV infections transmitted by Culex mosquitoes [19-23]. Birds are a predominant blood meal source for both $C x$. restuans and $C x$. pipiens across a variety of habitat types and regions [24-26]. Culex pipiens pipiens (Linnaeus 1758), which prospers in highnutrient urban habitat as juveniles [6, 20, 27], is a primary human WNV vector, possibly because it shifts between zoophilic and anthropophilic cycles seasonally [14, 23].

Aedes albopictus (Skuse, 1894), more commonly known as the Asian tiger mosquito, has spread globally over the last three decades since its expansion from Southeast Asia to the Americas and is now a predominant nuisance species in many temperate cities [28-31], with clear consequences for arboviral transmission. Autochthonous transmission of chikungunya and dengue viruses by Ae. albopictus has been documented in temperate and Mediterranean Europe [32-35] and Japan [36-38]. Studies from across its new geographical range suggest extensive feeding plasticity ranging from exclusive human biting in urban landscapes [39-41] to a more generalist diet including humans, wild and peridomestic mammals, birds and even amphibians/reptiles [39, 40, 42-44]. Research in New Jersey, USA found that although Ae. albopictus were predominantly anthropophilic, samples from neighborhoods where pets were more likely to be kept outside had a greater proportion of peridomestic mammalian hosts such as dogs and cats [44]. Unlike Culex vectors that may disperse several kilometers [45], Ae. albopictus remain close to juvenile habitat and few disperse more than 100 meters [46-49]. In urban neighborhoods where rowhome structures and paved streets can limit vector dispersal [50], non-human blood meal hosts could divert mosquitoes from human biting at fine spatial scales (e.g. zooprophylaxis [51, 52]).

Aedes japonicus japonicus (Theobald, 1901) was first detected in the United States in 1998 [53] and is a competent vector for several arboviruses, including WNV, eastern equine encephalitis, and La Crosse virus [5457]. Like Ae. albopictus, this species seems to be an opportunistic mammalian feeder, although there are few studies that have evaluated Ae. j. japonicus blood meal hosts in the field. One third of engorged females sampled in New Jersey had taken blood from humans, while over $50 \%$ of blood meals were from white-tailed deer [58]. Although it has been reported to bite humans and birds in Japan and in laboratory conditions [59], no avian hosts have been identified in recent field studies. Other mammalian hosts detected in the New Jersey study included horse and Virginia opossum.

In this study we sequenced host DNA collected from Aedes and Culex mosquitoes collected across socioeconomically distinct neighborhoods in Baltimore, MD, USA [29, 60]. Baltimore City is a mosaic of distinct neighborhoods, and socio-economic conditions where housing value, educational attainment, crime rates and even life expectancy can vary significantly across short spatial distances [61-63]. There are an estimated 16,000 standing vacant buildings in Baltimore and this abandoned infrastructure has been demonstrated to be productive habitat for mosquitoes and other pests $[29,60]$. Blood meal analyses are critical for elucidating the ecological roles of vertebrate host species in supporting mosquito population growth and pathogen transmission cycles. Identifying the composition of mosquito host species across neighborhoods with differing infrastructure management and residential socio-economic status (SES) conditions can help identify how availability and access to blood meal hosts vary across the urban landscape and influence variation in transmission potential.

\section{Methods}

\section{Study area}

We focused data collection in 5 neighborhoods that (i) consisted of row homes; (ii) were categorized as having household incomes (roughly \$15,000) Below, Above or at (Median) the City's median household income of $\$ 41,000$ (in 2010); and (iii) were more than one kilometer from two large City Parks (Druid Hill and Leakin Park) and the Inner Harbor (Fig. 1). Neighborhoods were identified using online data from Baltimore City and the US Census Bureau (http://bniajfi.org/ and https://www.census.gov). This work was conducted as part of a larger coupled natural human systems project designed to investigate mosquito and human systems in the context of individual and community actions and urban decay (i.e. population decline, abandoned lots and unmanaged refuse) in Baltimore, Maryland. For further information about neighborhood selection and confirmation of socio-economic status (SES), see [60]. Each of the five neighborhood boundaries varies in total area but city blocks within neighborhoods are relatively 


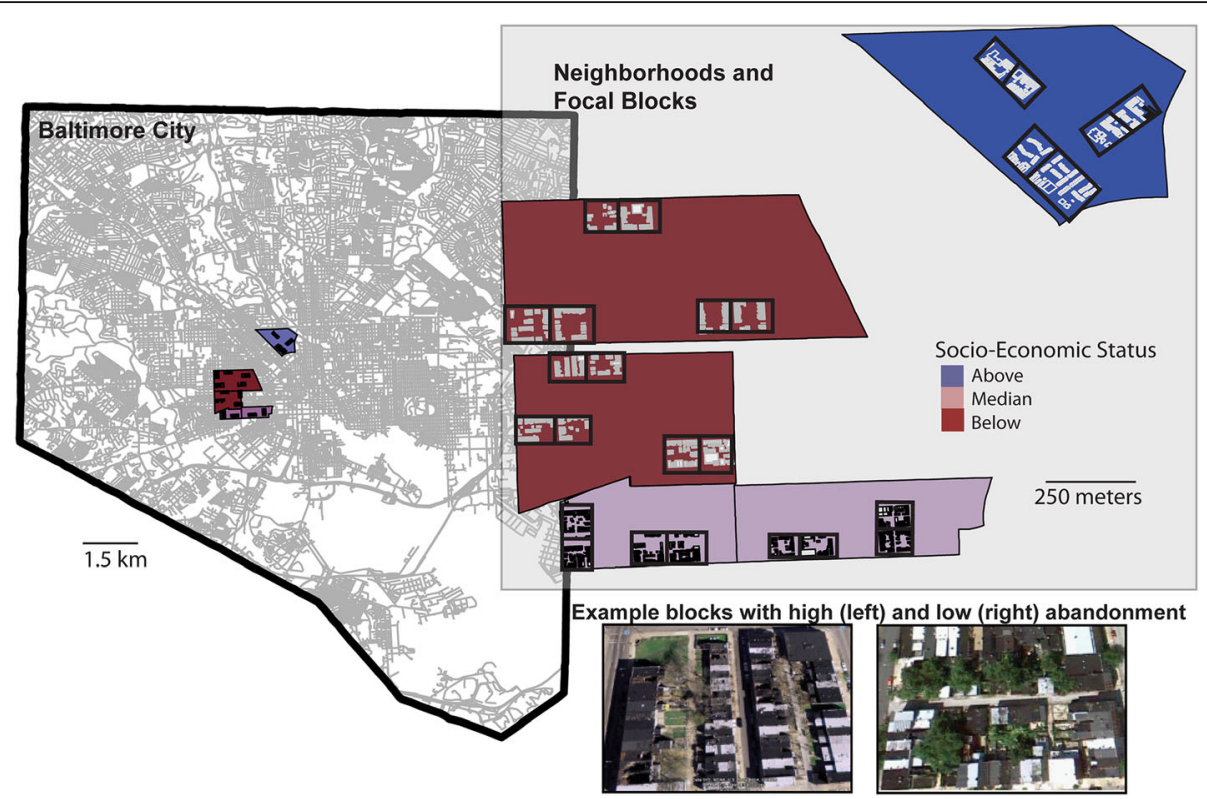

Fig. 1 Map of study neighborhoods and focal blocks in Baltimore City, Maryland, USA. Aerial images from Google Maps (Imagery@Google 2016) shown depict examples from the focal study area of blocks with high and low infrastructure abandonment

consistent in size (Table 1). We sampled adult mosquitoes intensively on $2-3$ blocks per neighborhood that were randomly selected from all blocks identified as predominantly residential (avoiding blocks with schools, large apartment complexes and businesses) and that were separated by at least one unsampled block (13 blocks total). Adults were only sampled on two blocks in the 'Median' category to maintain the minimum distance between blocks in these smaller neighborhoods. In addition to adult mosquito sampling, infrastructure condition metrics were recorded for each focal block, as described in [60].

\section{Surveillance}

BG-Sentinel ${ }^{\mathrm{TM}}$ traps baited with $\mathrm{CO}_{2}$ and a $2.0 \mathrm{ml}$ Octenol Lure (a mammal-derived attractant) were used to trap adult, blood-seeking mosquitoes in each study year. Traps were deployed at two locations on each focal block. While this trap was designed to target hostseeking Aedes, it has been demonstrated to effectively sample blooded specimens of both Aedes and Culex species when used with a BG lure [44]. A preliminary study in two of the focal neighborhoods collected greater numbers of both Culex and Aedes in the BG-Sentinel ${ }^{\mathrm{TM}}$ traps than in paired $C D C$ light traps, both baited with $\mathrm{CO}_{2}$ [64].

Trap sites were selected on each 0.5 block area to maximize distance between traps $(50-100 \mathrm{~m})$ and according to where researchers could establish property access. Trapping for 2015 and 2016 occurred on three blocks each in our 'Above' and 'Below' category SES neighborhoods and two each in the smaller 'Median' SES neighborhoods (Table 1). Traps were deployed and operational for $72 \mathrm{~h}$ every three weeks between May and October. After $24 \mathrm{~h}$, batteries, dry ice and catch bags were replaced at each trap. Mosquito catch bags were transported on dry ice and placed at $-20{ }^{\circ} \mathrm{C}$ until processed, which occurred within 2 weeks of each trap date. In 2015, the trapping cycle began May 26-27th and ended October 21-22nd, for a total of 8 trapping

Table 1 Neighborhood socio-economic status (SES), area, and sampling coverage

\begin{tabular}{|c|c|c|c|c|c|c|c|c|}
\hline Neighborhood & SES & $\begin{array}{l}\text { Median home price } \\
\text { (2016 US\$) }\end{array}$ & $\begin{array}{l}\text { NBHD } \\
\text { area }\left(\mathrm{km}^{2}\right)\end{array}$ & $\begin{array}{l}\text { Mean block } \\
\text { area }\left(\mathrm{km}^{2}\right)\end{array}$ & $\begin{array}{l}\text { Blocks ( } 2 \text { traps } \\
\text { per block) }\end{array}$ & $\begin{array}{l}\text { Per trap } \\
\text { area }\left(m^{2}\right)\end{array}$ & $\begin{array}{l}\text { Trap days (24-hour } \\
\text { trap periods) }\end{array}$ & $\begin{array}{l}\text { Mean occupancy (\% } \\
\text { parcels per block) }\end{array}$ \\
\hline Harlem Park & L & 16,500 & 0.808 & 0.026 & 3 & 12,888 & 168 & 0.457 \\
\hline $\begin{array}{l}\text { Franklin } \\
\text { Square }\end{array}$ & L & 21,250 & 0.451 & 0.021 & 3 & 10,311 & 168 & 0.505 \\
\hline Hollins Market & M & 67,000 & 0.277 & 0.018 & 2 & 9242 & 112 & 0.950 \\
\hline Union Square & M & 115,310 & 0.168 & 0.019 & 2 & 9561 & 112 & 0.785 \\
\hline Bolton Hill & $\mathrm{H}$ & 355,000 & 0.58 & 0.023 & 3 & 11,496 & 168 & 0.986 \\
\hline
\end{tabular}


sessions. Trapping in 2016 started June 6-7th and ended October 11-12th, for a total of 7 trapping sessions. Trapping efforts were ended when the total number of mosquitoes collected across all sites was less than 25 individuals.

Female mosquitoes from each trap were sorted by genus and enumerated. Female Aedes and some Culex mosquitoes were morphologically identified to species [65], and checked for the presence of a blood meal under a dissecting microscope. Culex pipiens and $C x$. restuans [66] were differentiated using a molecular assay during blood meal processing [67]. Each female mosquito with a visibly engorged abdomen was placed in a microcentrifuge tube with silica gel beads (Grade 48, 410 mesh size) and a small piece of cotton, and stored at room temperature $[68,69]$. Desiccation was chosen as the storage protocol due to lack of access to an ultra-low temperature $\left(-80{ }^{\circ} \mathrm{C}\right)$ freezer, although this may have limiting consequences on amplification success [70].

\section{Molecular processing and blood meal identification}

Abdomens were removed from blood-fed Culex and Aedes mosquitoes by using forceps to apply pressure between the thorax and abdomen against the wall of an Eppendorf tube. Between dissections forceps were dipped in $70 \%$ ethanol and passed through a flame to prevent cross-contamination. DNA from the blood in the abdomens was extracted using a Qiagen DNeasy Blood and Tissue kit (Qiagen Sciences, Germantown, MD, USA). To identify the source of the blood meals, we followed a protocol that first distinguishes human from non-human mammal-derived blood meals using a multiplex PCR assay developed for use in Ae. albopictus [71]. Samples that did not amplify with this assay were subjected to additional rounds of PCR screening with specific avian [72], mammalian [73] and reptile/amphibian [74] primers. Negative controls (PCR master mix and sterile water) were used to test for contamination in all reactions. With the exception of the speciesdiagnostic human band produced by the multiplex assay [71], all PCR products were cleaned and prepared for sequencing. Single bands were cleaned with Exo-Sap-IT (USB Products, Cleveland, OH, USA). In the case of a human/non-human mammal mix displaying two bands, the non-human band was excised from the gel and cleaned with a QIAquick Gel Extraction Kit (Qiagen Sciences, Germantown, MD, USA). Purified PCR products were cycle-sequenced with the forward primer of each pair and run on capillary automated sequencers (GenScript, Piscataway, NJ, USA). Sequences were entered in a BLAST search (Basic Local Alignment Search Tool) in GenBank to identify known species matches (> 98\% similarity) [68].
All statistical summaries and graphics were completed using the R Statistical Software package 3.3.1. We discuss differences in host-use and mosquito abundances across neighborhoods, making the assumption that there is modest exchange or dispersal between neighborhoods. This is based both on negative sampling results from roads between blocks and the correspondence of adult and juvenile abundances at the block scale [75]. We do not assume spatial independence between the two traps on a given block. Information from both traps on a block is combined in one per-trap-night estimate per sample period per block. Chi-square statistics were employed to assess significant differences in proportional host-use across across neighborhoods and SES category.

\section{Results}

A total of 20,551 adult female mosquitoes were collected across both years (49\% in 2016). Aedes albopictus made up $73.1 \%(n=15,023)$ of the total collected mosquitoes, 24.1\% $(n=4947)$ were Culex species, and $2.4 \%(n=531)$ were Ae. j. japonicus. Blood-fed mosquitoes were collected at 23 of the 26 trap sites and from all focal blocks. Fifty $(<1 \%)$ additional specimens were identified across the two years as Anopheles, Culiseta, Coquillettidia and Ae. aegypti. The majority of blooded mosquitoes were collected in July (Fig. 2). Blood fed females were generally more frequently sampled when total abundance was greatest, as for Culex and Ae. j. japonicus, although numbers of blood-fed Ae. albopictus was low in September despite persistently large populations (Fig. 2). Only one specimen with blood meals from multiple species was detected. One Ae albopictus collected in October from the Union Square neighborhood contained both human and cat DNA.

There were 208 (1.4\%) Ae. albopictus that were visibly engorged and we successfully extracted DNA and determined blood meal origin from 177 individuals (Table 2). The proportion engorged relative to total Ae. albopictus females was significantly lower in the 'Above' income neighborhoods $\left(\chi^{2}=25.91, d f=2, P<0.001\right)$ as compared to either the 'Median' or 'Below' category neighborhoods $(0.20 \%$ compared to $1.8 \%$ and $1.4 \%$, respectively). The proportion of engorged Ae. j. japonicus collected relative to total adult female Ae. j. japonicus ranged from $1.3-2.6 \%$ and was not significantly different across neighborhood SES $\left(\chi^{2}=0.67, d f=2, P=\right.$ $0.71)$. Aedes $j$. japonicus was only detected at our sites in July of either year. The brown rat (Rattus norvegicus) was the most frequently detected blood meal source in both Aedes species, making up $72 \%$ of all Ae. albopictus blood meals and $50 \%$ of Ae. j. japonicus host species (Table 2). Additional Ae. albopictus blood meals came from humans (14\%), domestic cats (12\%), dogs (1\%) and white-tailed deer $(<1 \%)$. Additional Ae. j. japonicus 

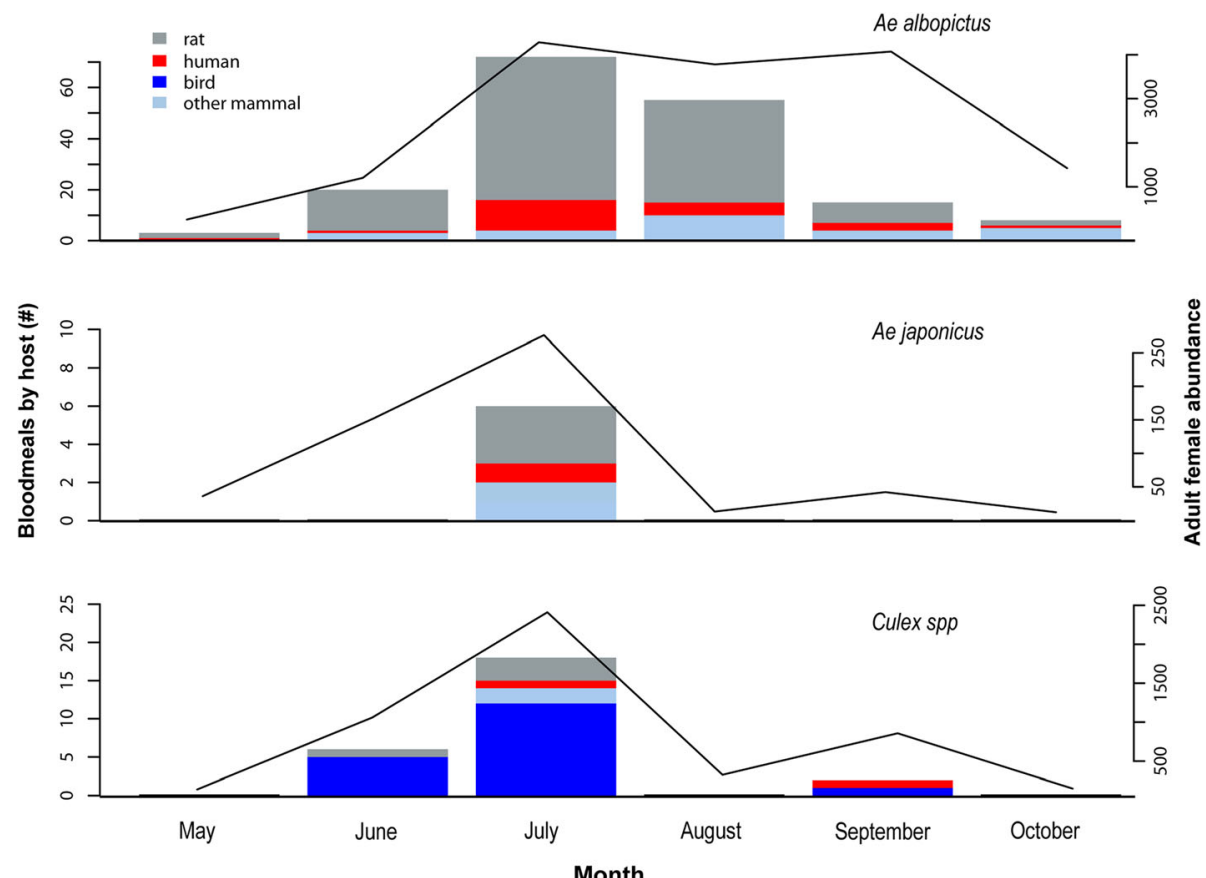

Fig. 2 Bars show the number of host blood meals by species group detected in Ae. albopictus, Ae. j. japonicus and pooled Culex specimens in each month (left axis) and are overlaid with total number of female mosquitoes of each species (solid lines, right axis)

hosts included an even split across human, white-tailed deer and cat (Table 2). There were no avian hosts detected in blood meals from either Aedes species.

There was a significantly lower proportion of Ae. albopictus blood meals taken from human hosts in the 'Below' category neighborhoods $\left(\chi^{2}=12.63, d f=2, P=\right.$ 0.002). Human blood made up the greatest proportion of total blood meals (50\%) in 'Above' SES sites and was lowest (6\%) in the 'Below' SES neighborhoods. Median income neighborhoods had significantly higher human blood meal proportions than the 'Below' income neighborhoods but were not significantly different from the 'Above' neighborhood samples (Fig. 3). SES category was not a significant predictor of relative proportions of $A e$. albopictus blood meals from any of the non-human sources.
We visually identified $82(1.7 \%)$ engorged Culex specimens and successfully determined blood meal origin for 26 individuals. The proportion engorged relative to total female Culex collected ranged from $1.2-2.5 \%$ and was not significantly different across neighborhood SES $\left(\chi^{2}=\right.$ 3.17, $d f=2, P=0.204)$. Blooded Culex samples included three species: $C x$. pipiens (65\%), Cx. restuans (12\%) and Cx. salinarius (23\%). Avian comprised $100 \%$ and $94 \%$ of $C x$. restuans and $C x$. pipiens hosts, respectively, while $C x$. salinarus hosts were entirely mammalian (Table 3 ). American robin (Turdus migratorius) was the most common avian blood meal source (44.4\%) and these were collected predominantly from the 'Below' SES sites (6 of 8). Other avian hosts included the American crow (Corvus brachyrhynchos, $n=1$ ), European starling (Sturnus vulgaris, $n=1$ ), gray catbird (Dumetella carolinensis,

Table 2 Percent host blood meals and number of sequences ( $n$ ) for Aedes species. Other Aedes albopictus hosts includes 2 dog blood meals from Franklin Square and 1 white-tailed deer blood meal from Harlem Park. A deer blood meal was also identified from Ae. j. japonicus in Union Square

\begin{tabular}{|c|c|c|c|c|c|c|c|c|c|}
\hline \multirow[t]{2}{*}{ Neighborhood } & \multirow[t]{2}{*}{ SES } & \multicolumn{4}{|c|}{ Ae. albopictus } & \multicolumn{4}{|c|}{ Ae. j. japonicus } \\
\hline & & Human $(n)$ & Rat $(n)$ & Cat $(n)$ & Other $(n)$ & Human $(n)$ & Rat $(n)$ & Cat $(n)$ & Other $(n)$ \\
\hline Franklin Square & L & $7.5(4)$ & $71.6(38)$ & $17.0(9)$ & $3.8(2)$ & $0(0)$ & $66.7(2)$ & $33.3(1)$ & $0(0)$ \\
\hline Harlem Park & L & $4.5(2)$ & $72.7(32)$ & $20.5(9)$ & $2.3(1)$ & $100(1)$ & $0(0)$ & $0(0)$ & $0(0)$ \\
\hline Hollins Market & M & $31.3(10)$ & $56.3(18)$ & $12.5(4)$ & $0(0)$ & $0(0)$ & $0(0)$ & $0(0)$ & $0(0)$ \\
\hline Union Square & M & $13.6(6)$ & $86.4(38)$ & $0(0)$ & $0(0)$ & $0(0)$ & $0(0)$ & $0(0)$ & $100(1)$ \\
\hline Bolton Hill & $\mathrm{H}$ & $50.0(2)$ & $50.0(2)$ & $0(0)$ & $0(0)$ & $0(0)$ & $100(1)$ & $0(0)$ & $0(0)$ \\
\hline Total area & & $13.6(24)$ & $72.3(128)$ & $12.4(22)$ & $1.7(3)$ & $16.7(1)$ & $50.0(3)$ & $16.7(1)$ & $16.7(1)$ \\
\hline
\end{tabular}




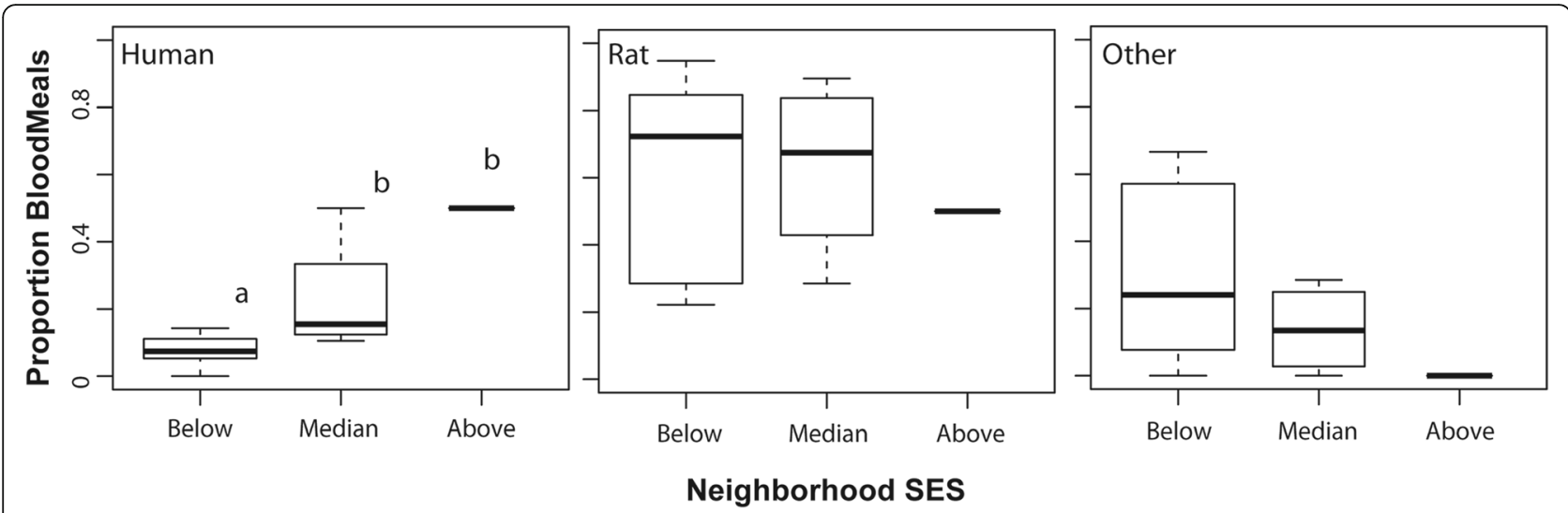

Fig. 3 Boxplots show median and quartile values for relative proportions of human, rat, and other mammals (cat, dog and deer) hosts detected in Ae. albopictus from each SES category

$n=2$ ), house sparrow (Passer domesticus, $n=1$ ), mourning dove (Zenaida macroura, $n=4$ ) and an unknown thrush (Turdidae, $n=1$ ). Human blood was only detected in Culex pipiens samples (6\%) both during peak abundance in July and again in September, when $C x$. pipiens population abundance was relatively low (Fig. 2). There were no statistical differences in the relative proportions of human or non-human blood meals from Culex sampled across the SES categories.

\section{Discussion}

This study highlights fine-scale variation in mammalian and avian host-use by medically important mosquito vectors and specifically investigates blood meal composition at spatial scales relevant to urban mosquito dispersal and human exposure. Further, the work emphasizes the importance of neighborhood socio-economic status and physical condition in shaping both the relative abundance of vectors and their local affinity for avian, mammalian and especially, human blood hosts.

The primary WNV vectors in the region, $C x$. pipens and $C x$. restuans, were predominantly ornithophagic, consistent with previous work $[23,44,76]$. The most frequently identified avian DNA was from the American robin, a known WNV reservoir and amplification species
$[23,27]$. However, while American robin blood was detected in specimens from all five neighborhoods, human blood meals were only found in $C x$. pipiens collected from 'Below' SES sites. Culex species tend to bite at dawn and dusk, unlike the daytime biting Aedes, and it is not clear whether this reflects differences in dawn and dusk access to humans across neighborhoods or is just a stochastic result of small sample size. The small number of engorged Culex specimens $(0.5 \%$ of total females collected) may indicate need for amending sampling and processing protocols to either attract more blooded Culex or better preserve the collections prior to PCR. Resting traps were trialed in our study sites but yielded no blooded Culex. Culex species may disperse several kilometers from juvenile breeding sites to find blood meal hosts. While we do find all three adult Culex species in our juvenile sampling across these same neighborhoods [29], it is likely that there is movement between neighborhoods to locate preferred hosts. While not the focus of the current study, future work will examine host-use of different avian species in the context of variable avian composition and abundance across different neighborhood SES conditions.

This work is consistent with previous studies that report opportunistic but mammalian-focused feeding

Table 3 Percent blood meal and sequence number ( $n$ ) for Culex species

\begin{tabular}{|c|c|c|c|c|c|c|c|c|c|c|c|}
\hline \multirow[t]{2}{*}{ Neighborhood } & \multirow[t]{2}{*}{ SES } & \multicolumn{3}{|l|}{ Cx. restuans } & \multicolumn{3}{|l|}{ Cx. pipiens } & \multicolumn{4}{|l|}{ CX. salinarius } \\
\hline & & Human (n) & Avian (n) & Rat (n) & Human $(n)$ & Avian (n) & Rat $(n)$ & Human (n) & Avian (n) & Rat $(n)$ & Cat $(n)$ \\
\hline Franklin Square & L & $0(0)$ & $100(1)$ & $0(0)$ & $12.5(1)$ & $87.5(7)$ & $0(0)$ & $0(0)$ & $0(0)$ & $0(0)$ & $0(0)$ \\
\hline Harlem Park & L & $0(0)$ & $100(1)$ & $0(0)$ & $0(0)$ & $100(3)$ & $0(0)$ & $0(0)$ & $0(0)$ & $66.6(2)$ & $33.3(1)$ \\
\hline Hollins Market & M & $0(0)$ & $0(0)$ & $0(0)$ & $0(0)$ & $100(3)$ & $0(0)$ & $0(0)$ & $0(0)$ & $0(0)$ & $0(0)$ \\
\hline Union Square & M & $0(0)$ & $100(1)$ & $0(0)$ & $0(0)$ & $100(1)$ & $0(0)$ & $0(0)$ & $0(0)$ & $100(1)$ & $0(0)$ \\
\hline Bolton Hill & $\mathrm{H}$ & $0(0)$ & $0(0)$ & $0(0)$ & $0(0)$ & $100(2)$ & $0(0)$ & $0(0)$ & $0(0)$ & $0(0)$ & $100(1)$ \\
\hline Total area & & $0(0)$ & $100(3)$ & $0(0)$ & $5.88(1)$ & $94.1(16)$ & $0(0)$ & $0(0)$ & $0(0)$ & $60(3)$ & $40(2)$ \\
\hline
\end{tabular}


strategies for Ae. albopictus and Ae. j. japonicus. However, we further demonstrate that host feeding by $A e$. albopictus in particular differs significantly across SES categories. Aedes albopictus dispersal is generally less than 100 meters, or the distance across one of our city blocks $[46,77]$. Thus, our results indicate that a female Ae. albopictus that developed on a higher income block is more likely to take a human blood meal than a mosquito emerging on a lower income block. However, vectorial capacity (and thus, transmission risk) is also a function of vector abundance [7, 13]. Female Ae. albopictus abundance has previously been associated with SES category in these same neighborhoods - with greatest abundance on lower income blocks that have high infrastructure abandonment $[29,60]$. The greatest capacity for vector transmission of pathogens among humans occurs where both vector abundance and human host-use are maximized. In this system these conditions are both maximized in the median income neighborhoods where Ae. albopictus abundance is greater than in neighborhoods with higher SES and human blood meal proportion is higher than in the lower income neighborhoods (e.g. Fig. 3). We believe that the greater proportion of abandoned infrastructure in the lower income neighborhoods, where proportion of buildings occupied ranged from 23-54\% (mean 37\%) across individual blocks, indicates a loss of access to human blood meals that is further reduced because remaining residents are less likely to spend time in backyards or shared green space (LaDeau, unpublished data). By comparison, a greater proportion of homes in the 'Median' category neighborhoods were occupied 69-96\% (mean $83.5 \%$ ) and residents were generally more likely to use local community gardens and shared green spaces (LaDeau, unpublished data). This study suggests that the relevant parameters necessary to understand vectorial capacity and both the rate and frequency of arboviral transmission in the urban landscape vary significantly at fine scales within and between urban neighborhoods. Perhaps more importantly, the current study indicates that knowing something about local infrastructure management and resident behavior may help guide management strategies and generate testable hypotheses for where transmission is most likely.

The invasive brown rat (also called Norway rat) is an important blood meal source across vector species and neighborhoods in Baltimore. Brown rats are a globally ubiquitous rodent in urban ecosystems, inhabiting sewer systems and dirt burrows. Urban rats have short dispersal distances and population structure is evident even at the scale of a city block [78]. Although most rat activity occurs just before or at sunset when Culex species feed, younger rats forage earlier in the day to avoid competing with larger, dominant rats [79]. This may make them more susceptible to being bitten by Aedes, as both Ae. albopictus and Ae. j. japonicus are daytime feeders. In 2004, researchers described a large, persistent brown rat population in Baltimore, MD, and trapped a majority of rats from alleys categorized as being in lower income neighborhoods [80]. Nearly $50 \%$ of the trapped rats across all sites tested positive for Seoul virus, a hantavirus that has also been detected locally in humans [81]. Rats are known reservoirs for other pathogens as well, including Salmonella, Leptospira, Rickettsia and Bartonella [82-86] and may be effective reservoirs for some arboviruses [87-89].

Samples from below SES neighborhoods included both a higher proportion and greater number of rat blood meals detected. This is consistent with being where the rat populations are believed to be most abundant [80]. These lower income neighborhoods are visibly characterized by infrastructure abandonment. Abandonment is evident in boarded doors and windows and in some cases, missing roofs (Fig. 1), but also because of the unmanaged refuse that is often illegally dumped by people external to the neighborhood. Previous work by this group has shown that these conditions support high numbers of unmanaged containers that are important habitat for immature development and production of adult Culex and Aedes populations [29, 60]. The majority of cat blood meals also were found in these lower income sites (Table 2), where feral cats have been fed and even encouraged in response to the rat problem. The current study raises important questions about the role of rat populations in supporting urban mosquito populations, the possibility of rat-prophylaxis (diversion of bites from humans) as well as their potential to act as pathogen reservoirs. It is unknown, for instance, whether a mosquito that bites a rat is more likely to feed to repletion before being disturbed or have different fitness consequences than a mosquito that bites a human. Understanding the mechanistic role that rodents play in feeding urban mosquito populations is important for predicting how pest management interventions and changes in infrastructure might influence mosquito abundances and human biting pressure.

Although Ae. albopictus has been endemic in the Baltimore region for nearly three decades, Ae. j. japonicus was only detected in Maryland in 2000. This relative newcomer, was less abundant across all focal neighborhoods and only six engorged females were sampled over the two years of the study. Despite the low number of blood-fed Ae. j. japonicus examined, the blood sources identified included the range of hosts seen in the more abundant and widespread Ae. albopictus. We identified one human blood meal in Ae. j. japonicus and though detection of human feeding in this species is not new [58], the opportunistic nature of its blood feeding 
behavior implicates it as a potentially important vector for La Crosse virus or other zoonoses with small mammal reservoirs $[2,56,90]$.

The socio-economic indicators of arboviral transmission risk are complex and can covary with environmental drivers, such as temperature and precipitation [60, 64, 91, 92]. Furthermore, while higher SES neighborhoods often have lower human population densities due to larger residential footprints, urban population loss across many temperate cities is often focused in lower income neighborhoods [63]. Abundant mosquito vectors developing in the abandoned infrastructure across these neighborhoods may be less likely to encounter a human at all much less twice, as would be needed to first acquire and then transmit a non-zoonotic virus. Furthermore, this group has found that the residents in lower income Baltimore neighborhoods were more likely to spend time in the front of the row homes, where streets are paved and there is little shade or water-holding habitat for mosquitoes. By contrast, residents in higher income neighborhoods were more likely to maintain personal recreation space behind the home and to report perceived mosquito nuisance while using these spaces $[29,75]$. Assessing vectorial capacity in these complex urban landscapes requires some fine-scale geographical understanding of the biophysical and socio-economic conditions and human behaviors that influence juvenile and adult mosquito life stages.

\section{Conclusions}

This study demonstrates how fine-scale variation in host-use by medically important mosquito vectors can define a gradient in human exposure to mosquitoes and associated arboviruses across city neighborhoods. Further, the work emphasizes the importance of neighborhood socio-economic status and infrastructure management in shaping both the relative abundance of vectors and local affinity for avian, mammalian and especially, human blood meals. The greatest capacity for vector transmission of pathogens among humans occurs where both vector abundance and human host-use are maximized. In Baltimore this is in the median income neighborhoods where heterogeneous land management supports higher mosquito abundance than in high SES neighborhoods but resident use of outdoor spaces likely supports higher proportion human blood hosts than in low income neighborhoods. The invasive brown rat is an important blood source across vector species and sites, although it is a most frequent blood host in lower income neighborhoods. The current study raises important questions about how variation in rodent abundance and access to humans across the urban landscape can influence mosquito population growth, human biting pressure and potential transmission of endemic and emergent arboviruses.

\section{Acknowledgements \\ We are grateful to Joel Baker, Danielle Bodner, Eve Suzuki, and Eliza Little for significant contributions to field work, to Drs Dawn Biehler, Rebecca Jordan and Sacoby Wilson for support in the broader $\mathrm{CNH}$ project, and to Dr. Rick Ostfeld for providing comments on the manuscript.}

\section{Funding}

The authors recognize the financial support of the National Science Foundation Baltimore Ecosystem Study (NSF-LTER DEB 1027188) and the NSF Coupled Natural Human Systems Program (DEB 1211797).

\section{Availability of data and materials}

Data supporting the conclusions of this article are included within the article. Raw sequence data are available as Supplementary Material.

\section{Authors' contributions}

SLL, PTL and HG designed the study. HG, AE and DMF conducted and interpreted molecular analyses. HG, AE and SLL wrote the manuscript. All authors read and approved the final manuscript.

Ethics approval and consent to participate

Not applicable.

Consent for publication

Not applicable.

\section{Competing interests}

The authors declare that they have no competing interests.

\section{Publisher's Note}

Springer Nature remains neutral with regard to jurisdictional claims in published maps and institutional affiliations.

\section{Author details \\ ${ }^{1}$ Cary Institute of Ecosystem Studies, Millbrook, NY 12545, USA. ${ }^{2}$ Monmouth County Division of Mosquito Control, Tick-Borne Disease Laboratory, New Brunswick, NJ 08901, USA. ${ }^{3}$ Center for Vector Biology, Entomology Department, Rutgers University, New Brunswick, NJ 08901, USA. ${ }^{4}$ Department of Environmental Science and Technology, University of Maryland, College Park, MD 20742, USA.}

Received: 16 October 2017 Accepted: 6 March 2018

Published online: 10 April 2018

\section{References}

1. Juliano SA, Lounibos LP. Ecology of invasive mosquitoes: effects on resident species and on human health. Ecol Lett. 2005:8:558-74.

2. Benedict MQ, Levine RS, Hawley WA, Lounibos LP. Spread of the tiger: Global risk of invasion by the mosquito Aedes albopictus. Vector-Borne and Zoonotic Diseases. 2007;7:76-85.

3. Rochlin I, Turbow D, Gomez F, Ninivaggi DV, Campbell SR. Predictive mapping of human risk for West Nile virus (WNV) based on environmental and socioeconomic factors. PLoS One. 2011;6:e23280.

4. Vazquez-Prokopec GM, Eng JLV, Kelly R, Mead DG, Kolhe P, Howgate J, et al. The risk of West Nile virus infection is associated with combined sewer overflow streams in urban Atlanta, Georgia, USA. Environ Health Persp. 2010;118:1382-8.

5. Weaver SC, Reisen WK. Present and future arboviral threats. Antivir Res. 2010;85:328-45.

6. Fonseca DM, Keyghobadi N, Malcolm CA, Mehmet C, Schaffner F, Mogi M, et al. Emerging vectors in the Culex pipiens complex. Science. 2004;303: 1535-8

7. LaDeau SL, Allan BF, Leisnham PT, Levy MZ. The ecological foundations of transmission potential and vector-borne disease in urban landscapes. Funct Ecol. 2015;29:889-901. 
8. Cadenasso ML, Pickett STA, Schwarz K. Spatial heterogeneity in urban ecosystems: reconceptualizing land cover and a framework for classification. Front Ecol Environ. 2007;5:80-8.

9. Washburn JO. Regulatory factors affecting larval mosquito populations in container and pool habitats - implications for biological-control. J Am Mosquito Contr. 1995;11:279-83.

10. Rey JR, O'Meara GF, O'Connell SA, Cutwa-Francis MM. Factors affecting mosquito production from stormwater drains and catch basins in two Florida cities. J Vector Ecol. 2006;31:334-43.

11. Freed TZ, Leisnham PT. Roles of spatial partitioning, competition, and predation in the North American invasion of an exotic mosquito. Oecologia. 2014; 175:601-11.

12. Manore CA, Ostfeld RS, Agusto FB, Gaff H, LaDeau SL. Defining the risk of Zika and chikungunya virus transmission in human population centers of the eastern United States. PLoS Negl Trop Dis. 2017:11:e0005255.

13. Smith DL, Battle KE, Hay SI, Barker CM, Scott TW, McKenzie FE. Ross, Macdonald, and a theory for the dynamics and control of mosquitotransmitted pathogens. PLoS Pathog. 2012;8:e1002588.

14. Farajollahi A, Fonseca DM, Kramer LD, Kilpatrick AM. "Bird biting" mosquitoes and human disease: a review of the role of Culex pipiens complex mosquitoes in epidemiology. Infect Genet Evol. 2011;11:1577-85.

15. Takken W, Verhulst NO. Host preferences of blood-feeding mosquitoes. Annu Rev Entomol. 2013:58:433-53.

16. Bartlett-Healy K, Unlu I, Obenauer P, Hughes T, Healy S, Crepeau T, et al. Larval mosquito habitat utilization and community dynamics of Aedes albopictus and Aedes japonicus (Diptera: Culicidae). J Med Entomol. 2012;49: 813-24.

17. Unlu I, Farajollahi A, Healy SP, Crepeau T, Bartlett-Healy K, Williges E, et al. Area-wide management of Aedes albopictus: choice of study sites based on geospatial characteristics, socioeconomic factors and mosquito populations. Pest Manag Sci. 2011;67:965-74.

18. Dowling Z, Ladeau SL, Armbruster P, Biehler D, Leisnham PT Socioeconomic status affects mosquito (Diptera: Culicidae) larval habitat type availability and infestation level. J Med Entomol. 2013;50:764-72.

19. Reisen WK, Fang Y, Martinez VM. Avian host and mosquito (Diptera: Culicidae) vector competence determine the efficiency of West Nile and St. Louis encephalitis virus transmission. J Med Entomol. 2005;42:367-75.

20. Molaei G, Andreadis TA, Armstrong PM, Anderson JF, Vossbrinck CR. Host feeding patterns of Culex mosquitoes and West Nile virus transmission, northeastern United States. Emerg Infect Dis. 2006:12:468-74.

21. Egizi AM, Farajollahi A, Fonseca DM. Diverse host feeding on nesting birds may limit early-season West Nile virus amplification. Vector Borne Zoonotic Dis. 2014;14:447-53

22. Hamer GL, Chaves LF, Anderson TK, Kitron UD, Brawn JD, Ruiz MO, et al. Fine-scale variation in vector host use and force of infection drive localized patterns of West Nile virus transmission. PLoS One. 2011;6:e23767.

23. Kilpatrick AM, Kramer LD, Jones MJ, Marra PP, Daszak P. West Nile virus epidemics in North America are driven by shifts in mosquito feeding behavior. PLoS Biol. 2006:4:606-10.

24. Molaei G, Andreadis TG, Armstrong PM, Diuk-Wasser M. Host-feeding patterns of potential mosquito vectors in connecticut, USA: molecular analysis of blood meals from 23 species of Aedes, Anopheles, Culex, Coquillettidia, Psorophora, and Uranotaenia. J Med Entomol. 2008:45:1143-51.

25. Savage HM, Aggarwal D, Apperson CS, Katholi CR, Gordon E, Hassan HK, et al. Host choice and West Nile virus infection rates in blood-fed mosquitoes, including members of the Culex pipiens complex, from Memphis and Shelby County, Tennessee, 2002-2003. Vector-Borne Zoonot Dis. 2007;7:365-86.

26. Kilpatrick AM, Daszak P, Jones MJ, Marra PP, Kramer LD. Host heterogeneity dominates West Nile virus transmission. Proc R Soc B-Biol Sci. 2006;273: 2327-33.

27. Hamer GL, Kitron UD, Goldberg TL, Brawn JD, Loss SR, Ruiz MO, et al. Host selection by Culex pipiens mosquitoes and West Nile virus amplification. Am J Trop Med Hyg. 2009;80:268-78.

28. Delatte H, Deheca JS, Thiria J, Domerg C, Paupy C, Fontenille D. Geographic distribution and developmental sites of Aedes albopictus (Diptera: Culicidae) during a chikungunya epidemic event. Vector Borne Zoonotic Dis. 2008;8: 25-34.

29. LaDeau SL, Leisnham PT, Biehler D, Bodner D. Higher mosquito production in low-income neighborhoods of Baltimore and Washington, D.C. Understanding ecological drivers and mosquito-borne disease risk in temperate cities. Int J Environ Res Public Health. 2013;10:1505-26.
30. Rochlin I, Ninivaggi DV, Hutchinson ML, Farajollahi A. Climate change and range expansion of the Asian tiger mosquito (Aedes albopictus) in northeastern USA: implications for public health practitioners. PLoS One. 2013;8:e60874.

31. Kraemer MUG, Sinka ME, Duda KA, Mylne AQN, Shearer FM, Barker CM, et al. The global distribution of the arbovirus vectors Aedes aegypti and Ae. albopictus. eLife. 2015;4:e08347.

32. Bellini R, Medici A, Calzolari M, Bonilauri P, Cavrini F, Sambri V, et al. Impact of chikungunya virus on Aedes albopictus females and possibility of vertical transmission using the actors of the 2007 outbreak in Italy. PLoS One. 2012; 7:e28360.

33. Carrieri M, Angelini P, Venturelli C, Maccagnani B, Bellini R. Aedes albopictus (Diptera: Culicidae) population size survey in the 2007 chikungunya outbreak area in Italy: estimating epidemic thresholds. J Med Entomol. 2012:49:388-99.

34. Roiz D, Bousses P, Simard F, Paupy C, Fontenille D. Autochthonous chikungunya transmission and extreme climate events in southern France. PLoS Negl Trop Dis. 2015;9:e0003854.

35. Delisle E, Rousseau C, Broche B, Leparc-Goffart I, L'Ambert G, Cochet A, et al Chikungunya outbreak in Montpellier, France, September to October 2014 Eurosurveillance. 2015;20:8-13.

36. Tsuda Y, Maekawa Y, Ogawa K, Itokawa K, Komagata O, Sasaki T, et al. Biting density and distribution of Aedes albopictus during the September 2014 outbreak of dengue fever in Yoyogi Park and the vicinity of Tokyo metropolis, Japan. Jpn J Infect Dis. 2016;69:1-5.

37. Quam MB, Sessions O, Kamaraj US, Rocklöv J, Wilder-Smith A. Dissecting Japan's dengue outbreak in 2014. Am J Trop Med Hyg. 2016;94:409-12.

38. Kutsuna S, Kato Y, Moi ML, Kotaki A, Ota M, Shinohara K, et al. Autochthonous denque fever, Tokyo, Japan, 2014. Emerg Infect Dis. 2015;21: 517-20.

39. Munoz J, Eritja R, Alcaide M, Montalvo T, Soriguer RC, Fiquerola J. Hostfeeding patterns of native Culex pipiens and invasive Aedes albopictus mosquitoes (Diptera: Culicidae) in urban zones from Barcelona, Spain. J Med Entomol. 2011;48:956-60

40. Richards SL, Ponnusamy L, Unnasch TR, Hassan HK, Apperson CS. Hostfeeding patterns of Aedes albopictus (Diptera: Culicidae) in relation to availability of human and domestic animals in suburban landscapes of central North Carolina. J Med Entomol. 2006;43:543-51.

41. Valerio L, Marini F, Bongiorno G, Facchinelli L, Pombi M, Caputo B, et al. Host-feeding patterns of Aedes albopictus (Diptera: Culicidae) in urban and rural contexts within Rome Province, Italy. Vector Borne Zoonotic Dis. 2010; 10:291-4.

42. Ponlawat A, Harrington LC. Blood feeding patterns of Aedes aegypti and Aedes albopictus in Thailand. J Med Entomol. 2005:42:844-9.

43. Sawabe K, Isawa H, Hoshin K, Sasaki T, Roychoudhury S, Higa Y, et al. Hostfeeding habits of Culex pipiens and Aedes albopictus (Diptera: Culicidae) collected at the urban and suburban residential areas of Japan. J Med Entomol. 2010:47:442-50

44. Faraji A, Egizi A, Fonseca DM, Unlu I, Crepeau T, Healy SP, Gaugler R. Comparative host feeding patterns of the asian tiger mosquito, Aedes albopictus, in urban and suburban northeastern USA and implications for disease transmission. PLoS Negl Trop Dis. 2014:8:e3037.

45. Johnson BJ, Fonseca DM. The effects of forced-egg retention on the bloodfeeding behavior and reproductive potential of Culex pipiens (Diptera: Culicidae). J Insect Physiol. 2014;66:53-8.

46. Marini F, Caputo B, Pombi M, Tarsitani G, Della Torre A. Study of Aedes albopictus dispersal in Rome, Italy, using sticky traps in mark-releaserecapture experiments. Med Vet Entomol. 2010;24:361-8.

47. Niebylski ML, Craig GB. Dispersal and survival of Aedes albopictus at a scrap tire yard in Missouri. J Am Mosquito Contr. 1994;10:339-43.

48. Liew C, Curtis CF. Horizontal and vertical dispersal of dengue vector mosquitoes, Aedes aegypti and Aedes albopictus, in Singapore. Med Vet Entomol. 2004:18:351-60

49. Ciota AT, Drummond CL, Ruby MA, Drobnack J, Ebel GD, Kramer LD. Dispersal of Culex mosquitoes (Diptera: Culicidae) from a wastewater treatment facility. J Med Entomol. 2012;49:35-42.

50. Barbu CM, Hong A, Manne JM, Small DS, Calderon JEQ, Sethuraman K, et al. The effects of city streets on an urban disease vector. PLoS Comput Biol. 2013:9:e1002801.

51. Bogh C, Clarke SE, Pinder M, Sanyang F, Lindsay SW. Effect of passive zooprophylaxis on malaria transmission in the Gambia. J Med Entomol. 2001;38:822-8. 
52. Franco AO, Gomes MGM, Rowland M, Coleman PG, Davies CR. Controlling malaria using livestock-based interventions: a One Health approach. PLoS One. 2014;9:e101699

53. Peyton EL, Campbell SR, Candeletti TM, Romanowski M, Crans WJ. Aedes (Finlaya) japonicus japonicus (Theobald), a new introduction into the united states. J Am Mosquito Contr. 1999;15:238-41.

54. Sardelis MR, Turell MJ, Andre ARG. Laboratory transmission of La Crosse virus by Ochlerotatus j. japonicus (Diptera: Culicidae). J Med Entomol. 2002; 39:635-9.

55. Sardelis MR, Dohm DJ, Pagac B, Andre RG, Turell MJ. Experimental transmission of eastern equine encephalitis virus by Ochlerotatus $j$. japonicus (Diptera: Culicidae). J Med Entomol. 2002;39:480-4.

56. Westby KM, Fritzen C, Paulsen D, Poindexter S, Moncayo AC. La Crosse encephalitis virus infection in field-collected Aedes albopictus, Aedes japonicus, and Aedes triseriatus in Tennessee. J Am Mosquito Contr. 2015:31:233-41.

57. Leisnham P, Juliano S. Impacts of climate, land use, and biological invasion on the ecology of immature Aedes mosquitoes: implications for La Crosse emergence. Ecohealth. 2012;9:217-28.

58. Molaei G, Farajollahi A, Scott JJ, Gaugler R, Andreadis TG. Human bloodfeeding by the recently introduced mosquito, Aedes japonicus japonicus, and public health implications. J Am Mosquito Contr. 2009;25: 210-4.

59. Tanaka K, Mizusawa K, Saugstad ESA. revision of the adult and larval mosquitoes of Japan (including the Ryukyu Archipelago and the Ogasawara Islands) and Korea (Diptera: Culicidae). Contrib. Am Entomol Inst. 1979;16

60. Little E, Biehler D, Jordan RA, Leisnham P, Wilson S, LaDeau SL. Socioecological mechanisms supporting high densities of Ae. albopictus in Baltimore, MD. J Med Entomol. 2017:54:1183-92.

61. Schwarz K, Fragkias M, Boone CG, Zhou WQ, MCHale M, Grove JM, et al. Trees grow on money: urban tree canopy cover and environmental justice. PLoS One. 2015;10:e0122051.

62. Boone CG. An assessment and explanation of environmental inequity in Baltimore. Urban Geogr. 2002;23:581-95.

63. Gulachenski A, Ghersi BM, Lesen AE, Blum MJ. Abandonment, ecological assembly and public health risks in counter-urbanizing cities. Sustainability. 2016;8(5):491.

64. Becker B, Leisnham PT, LaDeau SL. A tale of two city blocks: differences in immature and adult mosquito abundances between socioeconomically different urban blocks in Baltimore (Maryland, USA). Int J Environ Res Public Health. 2014;11:3256-70.

65. Darsie R, Ward R. Identification and geographical distribution of the mosquitoes of North America, North of Mexico. Gainesville: University of Florida Press; 2005

66. Harrington LC, Poulson RL. Considerations for accurate identification of adult Culex restuans (Diptera: Culicidae) in field studies. J Med Entomol. 2008;45(1):1-8

67. Crabtree MB, Savage HM, Miller BR. Development of a species-diagnostic polymerase chain-reaction assay for the identification of Culex vectors of St. Louis encephalitis-virus based on interspecies sequence variation in ribosomal DNA spacers. Am J Trop Med Hyg. 1995;53:105-9.

68. Kent RJ. Molecular methods for arthropod bloodmeal identification and applications to ecological and vector-borne disease studies. Mol Ecol Resour. 2009:9:4-18.

69. Kent RJ, Norris DE. Identification of mammalian blood meals in mosquitoes by a multiplexed polymerase chain reaction targeting cytochrome $b$. Am J Trop Med Hyg. 2005;73(2):336-42.

70. Reeves LE, Holderman CJ, Gillett-Kaufman JL, Kawahara AY, Kaufman PE. Maintenance of host DNA integrity in field-preserved mosquito (Diptera: Culicidae) blood meals for identification by DNA barcoding. Parasit Vectors. 2016:9:503.

71. Egizi A, Healy SP, Fonseca DM. Rapid blood meal scoring in anthropophilic Aedes albopictus and application of pcr blocking to avoid pseudogenes. Infect Genet Evol. 2013;16:122-8.

72. Cicero C, Johnson NK. Higher-level phylogeny of new world vireos (Aves: Vireonidae) based on sequences of multiple mitochondrial DNA genes. Mol Phylogenet Evol. 2001;20:27-40

73. Ngo KA, Kramer LD. Identification of mosquito bloodmeals using polymerase chain reaction (PCR) with order-specific primers. J Med Entomol. 2003;40:215-22

74. Cupp EW, Zhang DH, Yue X, Cupp MS, Guyer C, Sprenger TR, Unnasch TR. Identification of reptilian and amphibian blood meals from mosquitoes in an eastern equine encephalomyelitis virus focus in central Alabama. Am J Trop Med Hyg. 2004;71:272-6.

75. Bodner D. The effectiveness of resident-based mosquito control through changes in knowledge and behaviors along a socioeconomic gradient. MSC Thesis, University of Maryland, Maryland, USA; 2015.

76. Molaei G, Andreadis TG, Armstrong PM, Bueno R, Dennett JA, Real SV, et al. Host feeding pattern of Culex quinquefasciatus (Diptera: Culicidae) and its role in transmission of West Nile virus in Harris County, Texas. Am J Trop Med Hyg. 2007;77:73-81.

77. Cianci D, Van den Broek J, Caputo B, Marini F, Della Torre A, Heesterbeek H, Hartemink N. Estimating mosquito population size from mark-releaserecapture data. J Med Entomol. 2013;50:533-42.

78. Gardner-Santana LC, Norris DE, Fornadel CM, Hinson ER, Klein SL, Glass GE. Commensal ecology, urban landscapes, and their influence on the genetic characteristics of city-dwelling norway rats (Rattus norvegicus). Mol Ecol. 2009;18:2766-78.

79. Feng AYT, Himsworth CG. The secret life of the city rat: a review of the ecology of urban norway and black rats (Rattus norvegicus and Rattus rattus). Urban Ecosyst. 2014;17:149-62.

80. Easterbrook JD, Shields T, Klein SL, Glass GE. Norway rat population in Baltimore, Maryland, 2004. Vector Borne Zoonotic Dis. 2005;5:296-9.

81. Glass GE, Watson AJ, Leduc JW, Childs JE. Domestic cases of hemorrhagicfever with renal syndrome in the United States. Nephron. 1994;68:48-51.

82. Himsworth CG, Bai Y, Kosoy MY, Wood H, DiBernardo A, Lindsay R, et al. An investigation of Bartonella spp., Rickettsia typhi, and Seoul hantavirus in rats (Rattus spp.) from an inner-city neighborhood of Vancouver, Canada: is pathogen presence a reflection of global and local rat population structure? Vector Borne Zoonotic Dis. 2015;15:21-6.

83. Firth C, Bhat M, Firth MA, Williams SH, Frye MJ, Simmonds P, et al. Detection of zoonotic pathogens and characterization of novel viruses carried by commensal Rattus norvegicus in New York City. Mbio. 2014;5:e01933-14.

84. Ayral F, Zilber AL, Bicout DJ, Kodjo A, Artois M, Djelouadji Z. Distribution of Leptospira interrogans by multispacer sequence typing in urban Norway rats (Rattus norvegicus): a survey in france in 2011-2013. PLoS One. 2015;10: e0139604.

85. Leibler JH, Zakhour CM, Gadhoke P, Gaeta JM. Zoonotic and vector-borne infections among urban homeless and marginalized people in the United States and Europe, 1990-2014. Vector Borne Zoonotic Dis. 2016;16:435-44.

86. Strand TM, Lohmus M, Vinnersten TP, Rasback T, Sundstrom K, Bergstrom T, Lundkvist A. Highly pathogenic Leptospira found in urban brown rats (Rattus norvegicus) in the largest cities of Sweden. Vector Borne Zoonotic Dis. 2015; 15:779-81.

87. Arrigo NC, Adams AP, Watts DM, Newman PC, Weaver SC. Cotton rats and house sparrows as hosts for North and South American strains of eastern equine encephalitis virus. Emerg Infect Dis. 2010;16:1373-80.

88. Olive MM, Goodman SM, Reynes JM. The role of wild mammals in the maintenance of Rift Valley fever virus. J Wildlife Dis. 2012;48:241-66.

89. Han BA, Schmidt JP, Bowden SE, Drake JM. Rodent reservoirs of future zoonotic diseases. Proc Natl Acad Sci USA. 2015;112:7039-44.

90. Harris MC, Dotseth EJ, Jackson BT, Zink SD, Marek PE, Kramer LD, et al. La Crosse virus in Aedes japonicus japonicus mosquitoes in the Appalachian Region, United States. Emerg Infect Dis. 2015;21:646-9.

91. Pecoraro HL, Day HL, Reineke R, Stevens N, Withey JC, Marzluff JM, Meschke JS. Climatic and landscape correlates for potential West Nile virus mosquito vectors in the Seattle region. J Vector Ecol. 2007;32:22-8.

92. Reisen WK, Carroll BD, Takahashi R, Fang Y, Garcia S, Martinez VM, Quiring R. Repeated West Nile virus epidemic transmission in Kern County, California, 2004-2007. J Med Entomol. 2009;46:139-57. 